\title{
Bisphosphonates, atherosclerosis and vascular calcification: update and systematic review of clinical studies
}

\author{
Carla Caffarelli' \\ Andrea Montagnani ${ }^{2}$ \\ Ranuccio Nuti' \\ Stefano Gonnelli' \\ 'Department of Medicine, Surgery \\ and Neuroscience, University of Siena, \\ Italy; ${ }^{2}$ Division of Internal Medicine, \\ General Hospital Misericordia, \\ Grosseto, Italy
}

\author{
This article was published in the following Dove Press journal: \\ Clinical Interventions in Aging \\ 30 October 2017 \\ Number of times this article has been viewed
}

Background: Epidemiologic and clinical data have suggested the existence of a biologic linkage between the bone system and the vascular system. Bisphosphonates (BPs) are effective inhibitors of bone resorption and are currently considered the drugs of choice for the prevention and treatment of osteoporosis and related fractures. Data from several publications have suggested that BPs may also be effective in reducing the atherosclerotic process and vascular calcification, but the results of these studies are contrasting. This review aimed to allow a better understanding of the relationships between BPs and atherosclerosis in humans.

Materials and methods: Electronic databases of Pubmed-Medline, Cochrane Library and SCOPUS from inception to June 30, 2016 were searched. The full texts of the articles potentially eligible were carefully assessed and reviewed. Finally, 20 studies were found to be eligible and were included in the systematic review. All included studies were published between 2000 and 2014.

Results: In several studies, etidronate limited the progression of aortic and coronary calcification in hemodialysis patients, whereas the nitrogen-containing-BPs given orally did not significantly reduce vascular calcifications in patients with chronic kidney disease, kidney trasplant or in those with osteoporosis. Nitrogen-containing-BPs present favorable effects both on vessel wall thickness and on arterial elasticity due to both a reduction in serum lipids and the interaction of BPs with the bone tissue, with the consequent release of bone turnover markers and cytokines into the bloodstream.

Conclusion: To sum up, the BPs seem to have the potential of influencing atherosclerosis and calcium homeostasis at the level of vascular walls with several possible mechanisms which may differ according to the type, potency, dosage and administration route of BPs. Additional studies are needed to specifically address the mechanism by which BP use could influence cardiovascular morbidity and mortality.

Keywords: bisphosphonates, atherosclerosis, vascular calcification, human studies

\section{Introduction}

In the past, osteoporosis and atherosclerosis were considered as separate entities with a similar increasing prevalence with aging. Recently, both epidemiologic and clinical studies have outlined that patients with low bone mineral density (BMD) are at significantly greater risk of developing cardiovascular disease (CVD) as well as unexpected cardiovascular events, more severe coronary atherosclerosis and vascular calcification. ${ }^{1-6}$ In addition, it is known that postmenopausal women with osteoporosis have an increased risk of developing cardiovascular events and that the increased risk is proportional to the severity of osteoporosis. ${ }^{7}$ These data have also suggested
Correspondence: Stefano Gonnelli Department of Medicine, Surgery and Neuroscience, University of Siena, Policlinico Le Scotte, Viale Bracci 2. 53100 Siena, Italy Tel +39057 7585468

Fax +39057 7233446

Email gonnelli@unisi.it (c) (1) (2) 2017 Caffarelli et al. This work is published and licensed by Dove Medical Press Limited. The full terms of this license are available at https://www.dovepress.com/terms.php
and incorporate the Creative Commons Atribution - Non Commercial (unported, v3.0) License (http://creativecommons.org/licenses/by-nc/3.0/). By accessing the work you BY NC and incorporate the Creative Commons Attribution - Non Commercial (unported, v3.0) License (http:///creativecommons.org/licenses/by-nc/3.0/). By accessing the work you
hereby accept the Terms. Non-commercial uses of the work are permitted without any further permission from Dove Medical Press Limited, provided the work is properly attributed. For permission for commercial use of this work, please see paragraphs 4.2 and 5 of our Terms (https://www.dovepress.com/terms.php).
s. 
a possible influence of drugs affecting bone metabolism on lipid and atherosclerosis mechanisms, or that drugs effective on the atherosclerosis process could also be efficacious in fracture prevention. ${ }^{3,4}$ Moreover, there is growing evidence that osteoporosis and atherosclerosis share not only common risk markers such as aging, smoking, reduced physical activity and menopause in women, but also some pathophysiologic mechanisms and some genetic causes. For example, mutations with loss of function of LRP6 in humans lead to increased plasma low-density lipoprotein-cholesterol (LDL-C), hypertension and osteoporosis. ${ }^{8}$

An initial interesting theory was that CVD and osteoporosis were linked by a common denominator, such as serum lipid profile, which could act in parallel on both vascular and bone cells. ${ }^{9}$ Some experimental data seemed to reinforce this concept showing an influence of lipids on osteoblasts and osteoclasts. ${ }^{10-12}$ However, an interesting observational study showed that in a multiple regression analysis, lipid profile did not predict osteoporosis or fracture risk, whereas aortic calcification severity significantly explained BMD at the hip. ${ }^{13}$ On the other hand, low BMD at the distal radius was found to be associated with increased risk of stroke and CVD mortality. ${ }^{6}$ Several studies have reported that the progression of arterial calcification is linked with concurrent bone loss and vertebral fractures, further supporting a relationship between osteoporosis and CVD..$^{14,15}$ The common finding of simultaneous vascular calcification and osteoporosis in individual patients suggests that local tissue factors could have a crucial role in the regulation of mineralization and cell differentiation. ${ }^{16}$ Cardiovascular calcification was conventionally viewed as an inevitable consequence of aging, but some landmark studies have demonstrated that it is a highly regulated process of mineralization which involves cellular and molecular signaling processes similar to those found in normal osteogenesis. ${ }^{17-20}$ The similarity of the molecular mechanisms in osteogenesis and vascular calcification has led to the knowledge that atherosclerotic calcification is an actively regulated process, not a passive mineralization. ${ }^{21}$ In fact, the mineral matrix of the plaque (hydroxyapatite) is identical to that found in bone and the process of vascular calcification, similar to bone remodeling, is a regulated process which includes both inductive and inhibitory mechanisms. ${ }^{22,23}$ Moreover, mineral deposits in atherosclerotic plaque result from several different pathways involving metabolic and/or inflammatory processes. ${ }^{24}$ The major factors influencing vascular atherosclerotic calcifications are listed in Table 1.
Table I Factors influencing vascular atherosclerotic calcification

\begin{tabular}{|c|c|c|}
\hline Factor & References & Action \\
\hline $\begin{array}{l}\text { BPM-2 and } \\
\text { BPM-4 }\end{array}$ & 25,26 & $\begin{array}{l}\text { Stimulates osteogenic differentiation by } \\
\text { acting on Wnt pathway }\end{array}$ \\
\hline MGP & 27,28 & $\begin{array}{l}\text { Antagonizes BMP-2 and prevents } \\
\text { vascular calcification }\end{array}$ \\
\hline Fetuin-A & 29,30 & $\begin{array}{l}\text { Fetuin-A accumulates at sites of vascular } \\
\text { calcification and inhibits hydroxyapatite } \\
\text { formation and vascular calcifications }\end{array}$ \\
\hline OPG & $31-38$ & $\begin{array}{l}\text { OPG prevents RANKL from binding } \\
\text { to its receptor } \\
\text { OPG inhibits vascular calcification in } \\
\text { animals; in humans, there is a positive } \\
\text { association between OPG and CV diseases }\end{array}$ \\
\hline RANKL & $|6,38-4|$ & RANKL stimulates vascular calcification \\
\hline OPN & $27,42,43$ & $\begin{array}{l}\text { Enhancer of atherosclerosis in animals } \\
\text { In humans, may attenuate vascular } \\
\text { calcification }\end{array}$ \\
\hline FGF23 & 44,45 & $\begin{array}{l}\text { Reduces serum phosphate levels } \\
\text { Biomarker of vascular calcification in } \\
\text { CKD patients }\end{array}$ \\
\hline Vitamin D & $46-48$ & $\begin{array}{l}\text { Regulates the response to inflammatory } \\
\text { cytokines } \\
\text { No evidence of any effects on vascular } \\
\text { calcification }\end{array}$ \\
\hline Ox-LDL & 49 & $\begin{array}{l}\text { Induces osteogenic and apoptosis- } \\
\text { mediated calcification of vascular cells }\end{array}$ \\
\hline
\end{tabular}

Abbreviations: BPM-2, bone morphogenetic protein-2; BPM-4, bone morphogenetic protein-4; CKD, chronic kidney disease; CV, cardiovascular; FGF23, fibroblast growth factor 23; MGP, matrix Gla-protein; OPG, osteoprotegerin; OPN, osteopontin; Ox-LDL, oxidized low-density lipoprotein; RANKL, receptor activator of nuclear factor kappa-B ligand.

\section{The effects of bisphosphonates on atherosclerotic plaque and vascular calcifications: experimental studies}

The growing evidence that atherosclerosis and osteoporosis share several pathophysiologic mechanisms reinforces the interest in pharmacologic agents which could inhibit bone loss and also provide benefits in terms of slowing the progression of atherosclerosis. At present, only bisphosphonates (BPs), currently considered the drug of choice for the prevention and treatment of osteoporosis, could have this potential. ${ }^{50-52}$ In a mouse model of glucocorticoid-induced osteoporosis, denosumab, a human monoclonal antibody targeting RANKL, reduced the progression of atherosclerosis. ${ }^{41}$ Moreover, a more recent study reported that denosumab reduced spontaneous and induced calcification in an in vitro porcine valvular interstitial cell model..$^{53}$ However, the analysis of 2,363 postmenopausal women with osteoporosis selected from the participants in the FREEDOM study and at high risk of cardiovascular events showed a 3-year denosumab treatment had no effect on the progression of aortic calcifications or on the incidence of cardiovascular 
adverse events, compared to placebo. ${ }^{54}$ Also, odanacatib, a cathepsin K inhibitor, may have an anti-atherosclerotic effect; but in 2016, the development of odanacatib was discontinued after analysis discovered an increased risk of cardiovascular events. ${ }^{55} \mathrm{BPs}$ are grouped into two classes according to their chemical structure and the molecular mechanism by which they inhibit osteoclast activity (Table 2). Members of the first generation of BPs are called simple BPs (S-BPs; clodronate and etidronate), while those of the second or newer generation are called nitrogen-containing BPs (N-BPs). The latter have a high affinity for the bone tissue where they bind to and inhibit the activity of farnesyl pyrophosphate synthase, a key regulatory enzyme in the mevalonic acid pathway, leading to osteoclast apoptosis. ${ }^{56}$ The first report of the effects of BPs on vascular calcification was published in the 1970s, with experiments showing inhibition of soft tissue calcification. ${ }^{57}$ The accumulation of BPs in atherosclerotic arteries may be due to either their binding to calcified atheromatous lesions or their internalization into phagocytosing cells (namely, the macrophages).${ }^{52}$ Etidronate was the first BP to demonstrate the suppression of atherosclerotic lesion formation in the arteries of both rats and pigs, although there was no reduction in serum calcium and cholesterol. ${ }^{58,59}$ Lomashvili et al ${ }^{50}$ found that etidronate significantly reduced the calcium content in rat aortae cultured in a medium containing warfarin to induce calcification, and suggested that S-BPs may prevent calcifications by blocking the apatite crystalsformation in the vessels as they do in the bone. ${ }^{50}$ Clodronate at high dosages, when administered to rabbits, also significantly reduced the area of atherosclerotic lesions in the aorta, total cholesterol and total calcium concentration in the aorta. ${ }^{52}$ S-BPs may directly inhibit metalloproteinases ${ }^{60}$ and the expression of tumor necrosis factor- $\alpha$, a cytokine that promotes osteoblastic differentiation of vascular cells and also inhibits calcium

Table 2 Different potential effects of simple bisphosphonates and nitrogen-containing bisphosphonates on vascular calcification Simple bisphosphonates Nitrogen-containing bisphosphonates Inhibit metalloproteinases Inhibit TNF- $\alpha$ Reduce efflux of calcium and phosphate Influence the activity of the vascular smooth muscle cell $\mathrm{NaPi}$ cotransporter

Promote osteoblastic Direct effects on the vessel wall

differentiation of vascular

cells

Inhibit calcium deposition in the atheromatous lesions Promote the activation of caspase- 3 and induce apoptosis of osteoclasts

Direct effects on formation of crystals on the vessel wall, such as pyrophosphate Induce osteoclast apoptosis by inhibiting the farnesyl pyrophosphate synthase

Abbreviation: TNF- $\alpha$, tumor necrosis factor alpha.

deposition in the atherosclerotic lesions ${ }^{61}$ Moreover, S-BPs can be metabolized by the phagocytes into non-hydrolyzable adenine-containing analogs of adenosine triphosphate, ${ }^{62}$ which inhibit adenine nucleotide translocase, thus promoting the activation of caspase- 3 and thereby leading to apoptosis of macrophages and osteoclasts. ${ }^{63}$ Several animal studies suggest that N-BPs also may have an inhibitory effect on vascular calcification and atherosclerosis process. Alendronate and ibandronate are reported to inhibit calcification of arteries and cardiac valves in rat models of warfarin-related calcification at doses comparable to those that inhibit bone resorption, without affecting serum calcium and phosphate levels. ${ }^{64}$ Moreover, in uremic rats fed with a low-protein diet, artery calcifications were prevented by treatment with ibandronate..$^{65}$ Another study reported that high doses of vitamin D were lethal to rats and caused excessive calcification of arteries, lungs, kidneys and cartilage; however, when subjects were given vitamin D plus ibandronate, soft tissue calcification was inhibited in all organs and death was prevented. ${ }^{66}$ Moreover, in monkeys, a 2-year treatment with pamidronate inhibited the development of diet-induced atherosclerosis without significant changes in serum cholesterol and calcium. ${ }^{67}$ The exact mechanism by which N-BPs inhibit vascular calcification is not fully clear. It may be by the inhibition of bone resorption, with reduced efflux of calcium and phosphate, thus limiting their availability for deposition in the vessels or their ability to influence the activity of the vascular smooth muscle cells NaPi cotransporter. ${ }^{68}$ Alternatively, N-BPs may have direct effects on the vessel wall and/or crystal formation. Another possible mechanism of action of N-BPs may be a reduction in serum cholesterol levels. To sum up, the experimental studies have confirmed the ability of BPs to reduce the formation of atherosclerotic plaques and to inhibit vascular calcifications. In animal studies, etidronate was the more potent inhibitor of vascular calcifications.

\section{The effects of BPs on atherosclerotic plaque and vascular calcifications: a systematic review of clinical studies}

This review aimed to collect and synthesize the available data, in order to allow a better understanding of the relationships between BPs and atherosclerosis/vascular calcifications in humans.

\section{Materials and methods}

A literature review was conducted from inception to June 30, 2016. Pubmed-Medline, Cochrane Library and SCOPUS databases were searched using the following search terms 
("bisphosphonates" or "etidronate" or "alendronate" or "risedronate" and so on) AND ("atherosclerosis" or" atherosclerotic plaque" or "cholesterol" or "vascular calcification").

\section{Study selection}

Studies were excluded if they were not available; they were on children, animals, in vitro or experimental studies, case reports, case series, letters to editor, comments, review articles; they were published in languages other than English; and they did not fulfill the objective of this review. Original studies were included if they met the following inclusion criteria: 1) being a clinical study; 2) investigating the impact of BPs on atherosclerosis, vascular calcification or serum cholesterol and 3) presentation of sufficient information on the study parameters at baseline and at the end of follow-up. Exclusion criteria were: 1) non-interventional studies; 2 ) observational and cross-sectional studies and 3) study duration of $<6$ months.

Eligible studies were reviewed and the following data were extracted: 1) first author's name; 2) year of publication; 3) study design; 4) study duration; 5) number of subjects in BP and control groups; 6) intervention assigned to the control group (placebo, non-active treatment or active treatment); 7) outcome measurements evaluated and 8) baseline and endstudy values for the study parameters.

\section{Characteristics of included studies}

After the multiple database search, 297 published studies were identified and the abstracts reviewed. The study selection process is shown in Figure 1. The full text of the 32 articles potentially eligible were carefully assessed and reviewed. Finally, 20 studies were found to be eligible and were included in the systematic review.

\section{Results}

The characteristics of the 20 studies included in the systematic review are presented in Table 3. The included studies were published between 2000 and 2014. Similar to animal experiments, which reported conflicting results for BP treatment of atherosclerosis and related vascular calcification, there have been varying responses in clinical studies.

\section{Effects of BPs an intima-media thickening and serum cholesterol}

More than a decade ago, Adami et al firstly reported a significant reduction in LDL-C and an increase in highdensity lipoprotein-cholesterol (HDL-C) in postmenopausal women treated with intravenous (i.v.) neridronate, whereas no significant changes were observed in total cholesterol. ${ }^{69}$

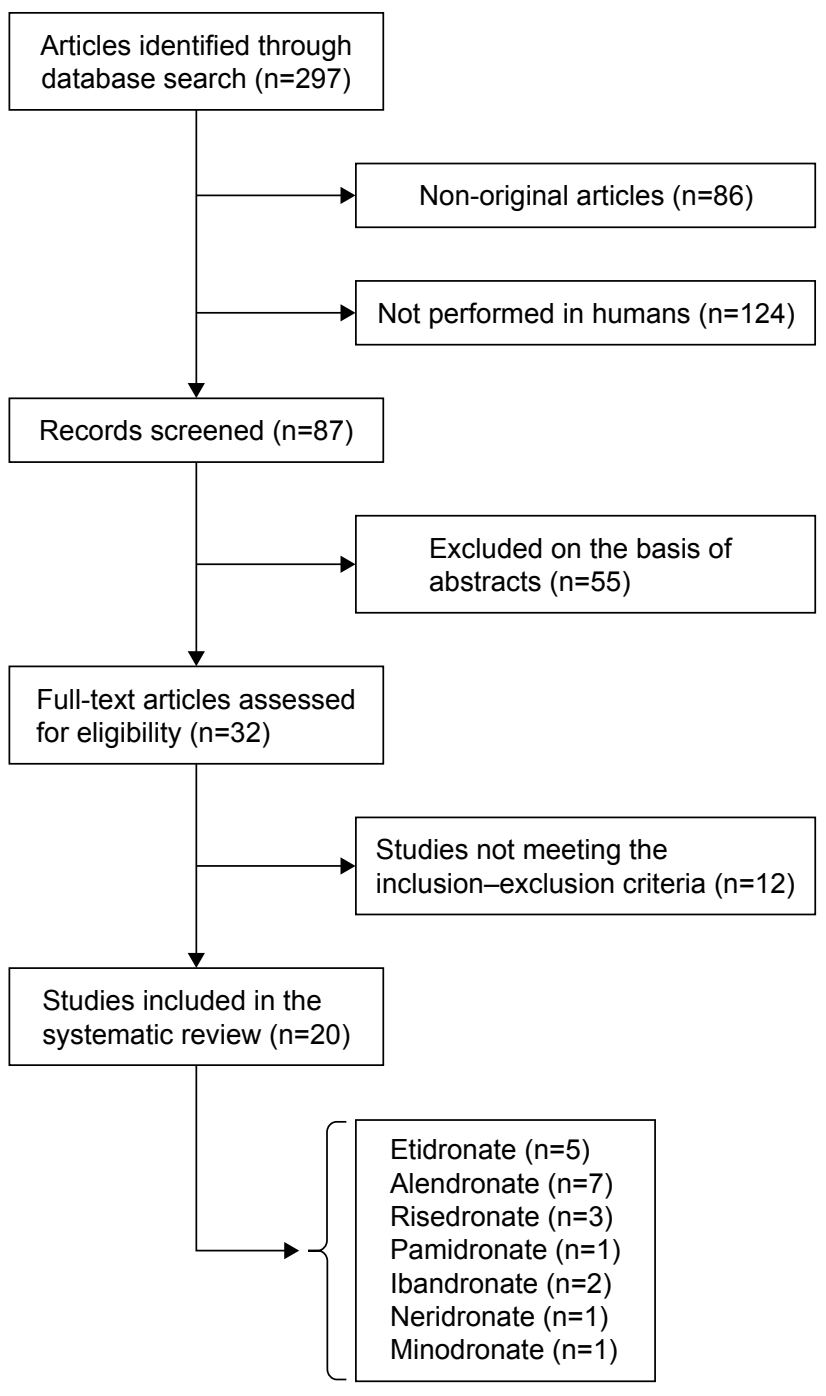

Figure I Flow chart of the studies identified and included in the review.

Significant reductions in LDL-C were also reported by other two clinical studies carried out, respectively, in patients treated with i.v. pamidronate for Paget's bone disease and in patients with smouldering multiple myeloma treated with zoledronic acid. ${ }^{70,71}$ More recently, Gonnelli et al reported that in postmenopausal osteoporotic women, a 1-year treatment with both zoledronate (a single yearly injection) and ibandronate (a 3-monthly injection) induced similar changes in lipid profile by increasing HDL-C and reducing LDL-C and resulted in a reduction of intima-media thickness (IMT) at the carotid artery; however, in the latter study, no significant changes in total cholesterol were observed. ${ }^{72}$ These positive effects of i.v. N-BPs on lipids have not yet been confirmed by the majority of studies carried out with N-BPs or S-BPs given orally. In particular, a study by Luckish et al carried out on osteoporotic women with at least one cardiovascular risk factor treated with risedronate $35 \mathrm{mg}$ weekly for 6 months reported a significant improvement in artery elasticity, but 


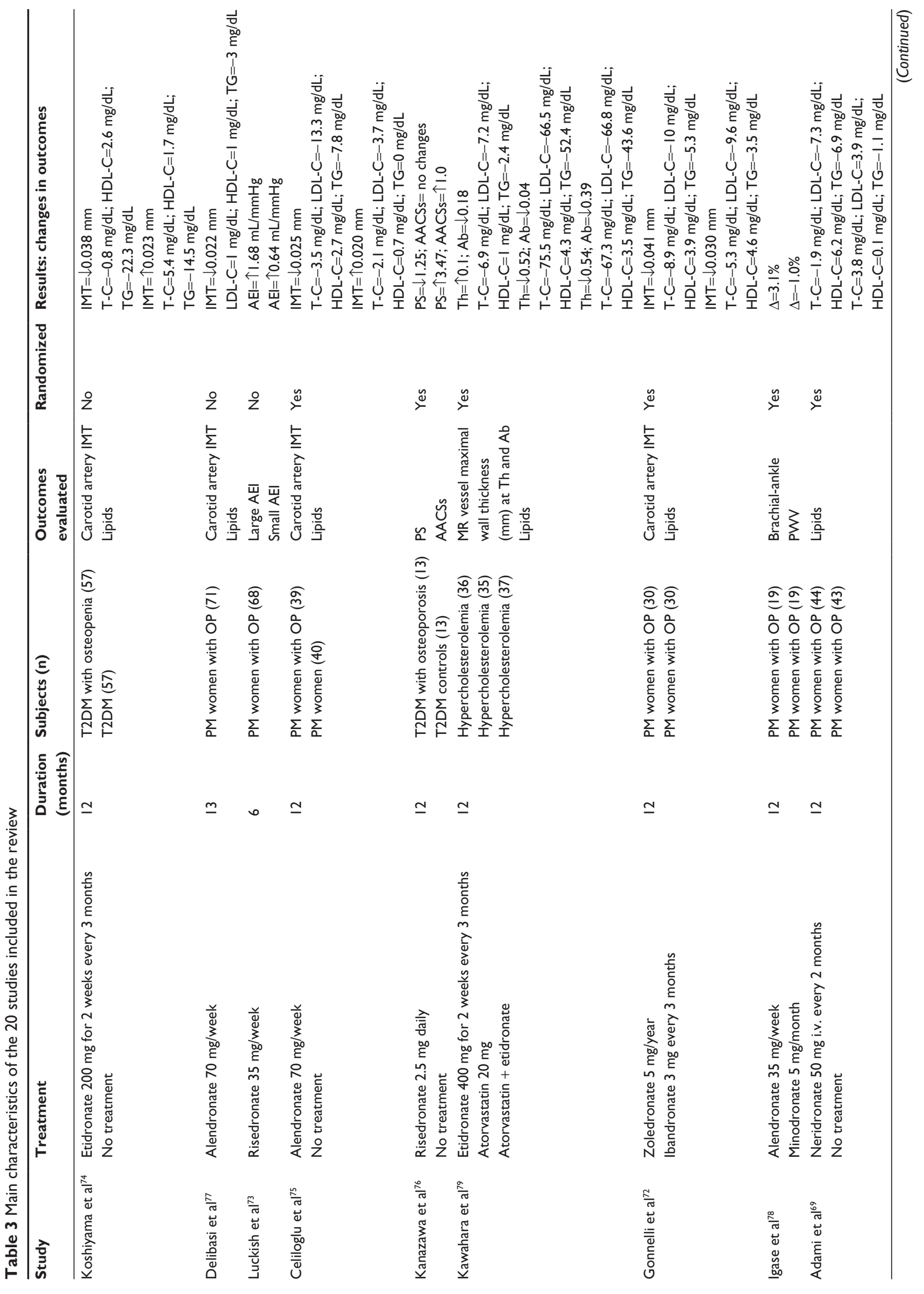




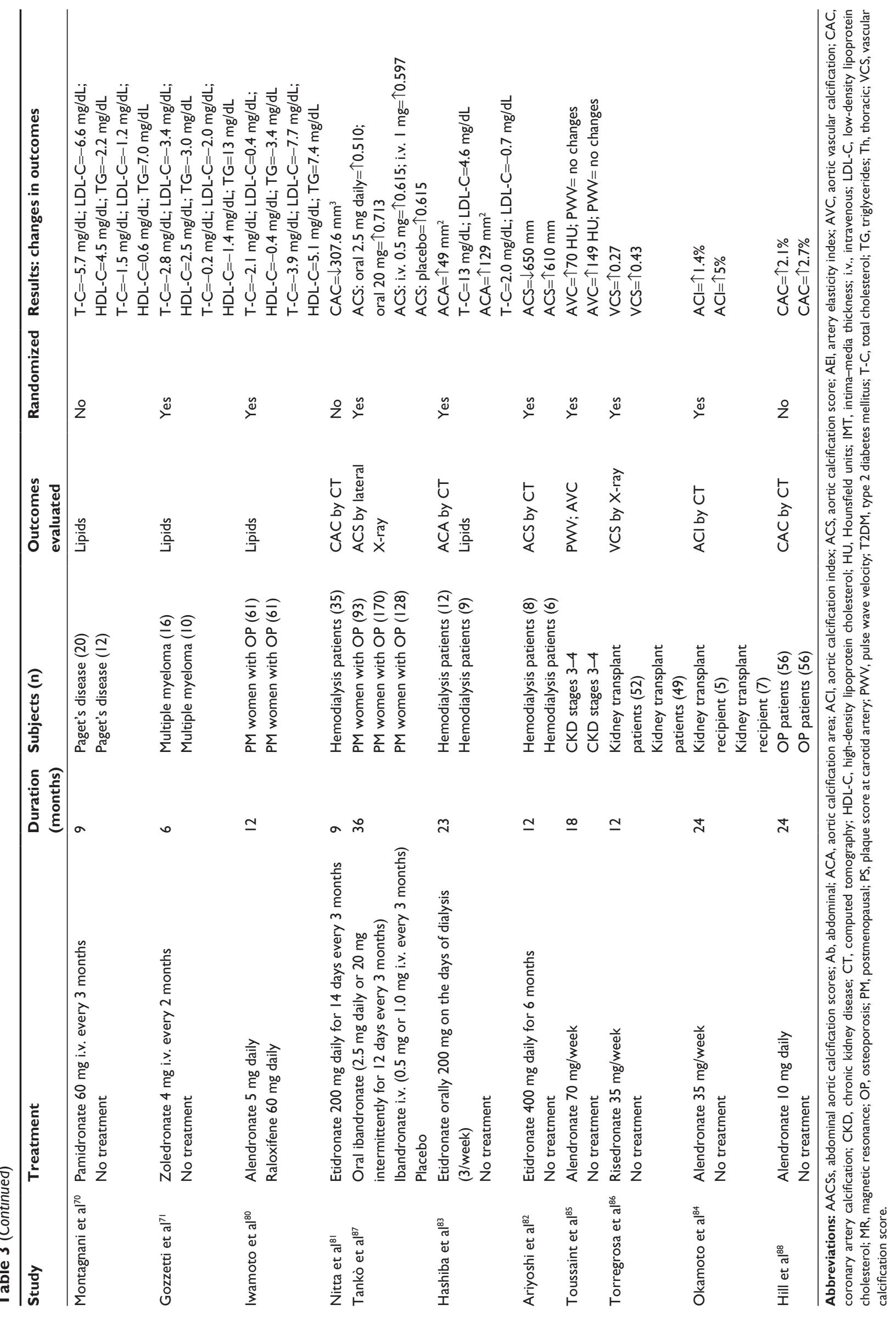


no change in HDL-C and LDL-C levels. ${ }^{73}$ Koshiyama et al ${ }^{74}$ investigated the effect of etidronate on carotid IMT in patients with type 2 diabetes and reported that at the end of a 12-month treatment, IMT was significantly reduced in the etidronate group with respect to control participants. Also, the study by Celiloglu et al reported that in postmenopausal osteoporotic women, a 1-year treatment with alendronate significantly reduced carotid IMT with respect to controls. ${ }^{75}$ Moreover, in a study carried out on Japanese women with diabetes and postmenopausal osteoporosis, a 1-year therapy with risedronate $(2.5 \mathrm{mg}$ /day) along with alfacalcidiol $(1 \mathrm{mg} /$ day) significantly reduced the progression of atherosclerotic plaques at the carotid arteries and abdominal aorta. ${ }^{76}$ On the contrary, the study by Delibasi et al reported that in postmenopausal osteoporotic women, a 13-month treatment with alendronate did not evidence any changes in carotid IMT or serum levels of lipids. ${ }^{77}$ Also, the study by Igase et al reported that in a Japanese population, a 1-year treatment with alendronate $(35 \mathrm{mg} /$ week) did not improve arterial stiffness. ${ }^{78}$ Some studies reported that a 12 -month treatment with etidronate $\mathrm{e}^{74,79}$ or alendronate ${ }^{75}$ induced a nonsignificant reduction in total and LDL-C, along with a nonsignificant increase in HDL-C. Moreover, Kawahara et al, in a prospective randomized study carried out in hypercholesterolemic patients, reported that atorvastatin plus etidronate combination therapy was significantly more effective $(P<0.001)$ in reducing atherosclerotic plaques in the abdominal aorta than both atorvastatin and etidronate monotherapy. ${ }^{79}$ In the same study, the atorvastatin plus etidronate combination therapy showed a reduction of the atherosclerotic plaques in thoracic aorta similar to that of atorvastatin monotherapy. ${ }^{79}$ On the contrary, a Japanese study carried out on osteoporotic women treated with a reduced dose of alendronate $(5 \mathrm{mg} /$ day) did not find any changes in cholesterol levels. ${ }^{80}$ To sum up, the majority of human studies have reported a reduction of IMT at the carotid artery, whereas data on arterial stiffness and the atherosclerotic plaques are inconclusive. Moreover, N-BPs seem to improve the lipid profile only when given i.v.

\section{Effects of BPs on vascular calcification}

Nitta et al reported that in hemodialysis patients, etidronate at a dose of $200 \mathrm{mg} /$ day for 2 weeks every 90 days significantly reduced coronary artery calcifications, assessed by spiral computed tomography, and serum levels of osteoprotegerin. ${ }^{81}$ In another study carried out on hemodialysis patients, etidronate (400 mg/day for 6 months) decreased aortic calcifications by $65 \%$, whereas aortic calcifications markedly increased in controls. ${ }^{82}$ Another Japanese study carried out on hemodialysis patients reported that etidronate $(200 \mathrm{mg}$ on days of dialysis for 23 months) protected against progression of aortic calcifications, whereas these significantly increased in the control group. ${ }^{83}$ A 2-year weekly treatment with alendronate in kidney transplant recipients was effective in preventing the progression of aortic calcifications with respect to control patients ( $1.4 \%$ vs $5 \%, P=\mathrm{ns}) .{ }^{84}$ Moreover, in a study carried out in end-stage chronic kidney disease (CKD) patients, an 18-month treatment with alendronate significantly decreased the progression of aortic calcification with respect to placebo.$^{85}$ Similarly, Torregrosa et al reported that 1-year treatment with residronate $(35 \mathrm{mg} /$ week) did not significantly influence the progression of vascular calcifications in kidney transplant patients. ${ }^{86}$ Another clinical study involved osteoporotic women receiving oral or i.v. ibandronate for 3 years; at the end of the study period, the effect on BMD was positive, whereas no difference was detected in the rate of aortic calcification change. ${ }^{87}$ Moreover, the study by Hill et al assessing coronary artery calcification, measured by spiral computed tomography scans, in patients treated with alendronate $10 \mathrm{mg}$ daily for 2 years matched to a cohort of reference subjects did not find any significant differences between the two groups. ${ }^{88}$ To sum up, etidronate markedly reduced progression of vascular calcifications, but most of these studies were carried out in patients with CKD or in hemodialysis. The effects of N-BPs given orally on the vascular calcifications were modest and inconclusive.

\section{Discussion}

The interest in the relationships between BPs and atherosclerosis has recently shown a further increase after the publication of the results of the HORIZON study which reported a $28 \%$ reduction in mortality in hip fracture patients treated with an annual i.v. dose of zoledronic acid..$^{89}$ In another study, Kang et al revealed that patients who received BP therapy for osteoporotic fracture had a lower hazard of myocardial infarction during the 2-year follow-up period with respect to controls..$^{90}$ Moreover, two recent studies have reported that oral BPs reduce mortality in osteoporotic patients and that the reduction in mortality could be mainly due to cardiovascular and cerebrovascular deaths. ${ }^{91,92}$ On the contrary, a recent meta-analysis by Kim et $\mathrm{al}^{93}$ indicated that commonly prescribed BPs do not provide any clinically important benefits or harm with regard to cardiovascular events. The analysis of the studies included in this systematic review seems to suggest a positive effect of BPs on the progression of both atherosclerotic plaque and vascular calcifications. First of all, it is important to emphasize that this review has some limitations primarily resulting from the small sample size of most studies. Thus, insufficient data were available 
to allow separate analysis of the effects of BPs in different patient subgroups. Moreover, most of these studies were of suboptimal quality in terms of providing adequate description of allocation concealment and the lack of the use of double blinding, thus leading to possible overestimation of $\mathrm{BP}$ benefit.

Several studies have shown that etidronate limited the progression of aortic and coronary calcification in hemodialysis patients. ${ }^{81-83}$ Instead, the N-BPs given orally (alendronate, risedronate and ibandronate) did not significantly reduce vascular calcifications either in patients with $\mathrm{CKD}^{85}$ and kidney trasplant ${ }^{86}$ or in patients with osteoporosis ${ }^{88}$ and hypercholesterolemia. ${ }^{79}$ However, at present, the clinical use of etidronate should be considered with caution because this agent can cause impaired bone mineralization, which may lead to osteomalacia and to an increased risk of stress fractures. Moreover, particular attention is required when using BPs in CKD and hemodialysis patients because in these patients, BPs may excessively reduce bone turnover, ultimately aggravating adynamic bone disease. Several studies have reported that BPs, especially N-BPs, present favorable effects both on vessel wall thickness and on the parameters of arterial elasticity and stiffness. ${ }^{72-76,79}$ A possible mechanism of action of N-BPs may be a slowing down of the formation of atherosclerotic plaques due to a reduction in serum lipids, which are considered responsible for the triggering of atherosclerosis progression. In fact, the majority of studies found a reduction in total and LDL-C along with a mild increase in HDL-C, ${ }^{69-72,74}$ whereas other studies did not report any changes. ${ }^{77,80}$ These controversial data may suggest that the effect of BPs on lipids depends on the administration route, with a more favorable effect found when given i.v. However, literature data suggest that the changes in lipids alone are not sufficient to explain the positive effect on atherosclerosis. Moreover, BPs, especially N-BPs, could have an indirect effect on atherosclerotic manifestations due to the interaction of BPs with the bone tissue, with the consequent release of bone turnover markers, bone-related hormones and cytokines (such as osteocalcin, fibroblast growth factor 23, osteoprotegerin and so on) into the bloodstream. As confirmation, a recent study reported that osteocalcin and fibroblast growth factor 23 were independent predictors of carotid IMT in postmenopausal women treated with zoledronate. ${ }^{72}$

To sum up, the BPs seem to have the potential of influencing atherosclerosis and calcium homeostasis at the level of vascular walls with several possible mechanisms which may differ according to the type, potency, dosage and administration route of BPs. However, until the present time, it is not yet clear which of these above-mentioned mechanisms may be the most important in humans and additional studies are needed to specifically address the mechanism by which BPs use could influence cardiovascular morbidity and mortality.

\section{Disclosure}

The authors report no conflicts of interest in this work.

\section{References}

1. Sinnott B, Syed I, Sevrukov A, Barengolts E. Coronary calcification and osteoporosis in men and postmenopausal women are independent processes associated with aging. Calcif Tissue Int. 2006;78(4): 195-202.

2. Von der Recke P, Hansen MA, Hassager C. The association between low bone mass at the menopause and cardiovascular mortality. Am J Med. 1999;106(3):273-278.

3. Esposito K, Capuano A, Sportiello L, Giustina A, Giugliano D. Should we abandon statins in the prevention of bone fractures? Endocrine. 2013;44(2):326-333.

4. Santos LL, Cavalcanti TB, Bandeira FA. Vascular effects of bisphosphonates-A systematic review. Clin Med Insights Endocrinol Diabetes. 2012;5:47-54.

5. Danilevicius CF, Lopes JB, Pereira RM. Bone metabolism and vascular calcification. Braz J Med Biol Res. 2007;40(4):435-442.

6. Kiel DP, Kauppila LI, Cupples LA, Hannan MT, O’Donnell CJ, Wilson PW. Bone loss and the progression of abdominal aortic calcification over a 25 year period: the Framingham Heart Study. Calcif Tissue Int. 2001;68(5):271-276

7. Tanko LB, Christiansen C, Cox DA, Geiger MJ, McNabb MA, Cummings SR. Relationship between osteoporosis and cardiovascular disease in postmenopausal women. J Bone Miner Res. 2005;20(11): 1912-1920.

8. Williams BO, Insogna KL. Where Wnts went: the exploding field of Lrp5 and Lrp6 signaling in bone. J Bone Miner Res. 2009;24(2): 171-178.

9. Baldini V, Mastropasqua M, Francucci CM, D’Erasmo E. Cardiovascular disease and osteoporosis. J Endocrinol Invest. 2005;(28 Suppl):69-72.

10. Parhami F, Basseri B, Hwang J, Tintut Y, Demer LL. High-density lipoprotein regulates calcification of vascular cells. Circ Res. 2002; 91(7):570-576

11. Parhami F, Garfinkel A, Demer LL. Role of lipids in osteoporosis. Arterioscler Thromb Vasc Biol. 2000;20(11):2346-2348.

12. Tintut Y, Morony S, Demer LL. Hyperlipidemia promotes osteoclastic potential of bone marrow cells ex vivo. Arterioscler Thromb Vasc Biol. 2004;24(2):e6-e10.

13. Bagger YZ, Rasmussen HB, Alexandersen P, Werge T, Christiansen C, Tankó LB; PERF study group. Links between cardiovascular disease and osteoporosis in postmenopausal women: serum lipids or atherosclerosis per se? Osteoporos Int. 2007;18(4):505-512.

14. Vogt MT, San Valentin R, Forrest KY, Nevitt MC, Cauley JA. Bone mineral density and aortic calcification: the study of osteoporotic fractures. J Am Geriatr Soc. 1997;45(2):140-145.

15. Hofbauer LC, Brueck CC, Shanahan CM, Schoppet M, Dobnig H. Vascular calcification and osteoporosis from clinical observation towards molecular understanding. Osteoporos Int. 2007;18(3):251-259.

16. Parhami F, Morrow AD, Balucan J, et al. Lipid oxidation products have opposite effects on calcifying vascular cell and bone cell differentiation. A possible explanation for the paradox of arterial calcification in osteoporotic patients. Arterioscler Thromb Vasc Biol. 1997;17(4): 680-687.

17. Aikawa E, Nahrendorf M, Sosnovik D, et al. Multimodality molecular imaging identifies proteolytic and osteogenic activities in early aortic valve disease. Circulation. 2007;115(3):377-386. 
18. Aikawa E, Aikawa M, Libby P, et al. Arterial and aortic valve calcification abolished by elastolytic cathepsin S deficiency in chronic renal disease. Circulation. 2009;119(13):1785-1794.

19. Bostrom K, Watson KE, Stanford WP, Demer LL. Atherosclerotic calcification: relation to developmental osteogenesis. Am J Cardiol. 1995; 75(6):88B-91B.

20. Duer MJ, Friscic T, Proudfoot D, et al. Mineral surface in calcified plaque is like that of bone: further evidence for regulated mineralization. Arterioscler Thromb Vasc Biol. 2008;28(11):2030-2034.

21. Demer LL, Tintut Y. Mineral exploration: search for the mechanism of vascular calcification and beyond: the 2003 Jeffrey M. Hoeg Award lecture. Arterioscler Thromb Vasc Biol. 2003;23(10):1739-1743.

22. Lusis AJ. Atherosclerosis. Nature. 2000;407(6801):233-241.

23. Bostrom K, Demer LL. Regulatory mechanisms in vascular calcification. Crit Rev Eukaryot Gene Expr. 2000;10(2):151-158.

24. Sage AP, Tintut Y, Demer LL. Regulatory mechanisms in atherosclerotic calcification. Nat Rev Cardiol. 2010;7(9):528-536.

25. Bostrom K, Watson KE, Horn S, Wortham C, Herman IM, Demer LL. Bone morphogenetic protein expression in human atherosclerotic lesions. J Clin Invest. 1993;91(4):1800-1809.

26. Steitz SA, Speer MY, Curinga G, et al. Smooth muscle cell phenotypic transition associated with calcification: up regulation of $\mathrm{Cbfa} 1$ and down regulation of smooth muscle lineage markers. Circ Res. 2001;89(12): 1147-1154.

27. Ikeda T, Shirasawa T, Esaki Y, Yoshiki S, Hirokawa K. Osteopontin mRNA is expressed by smooth muscle-derived foam cells in human atherosclerotic lesions of the aorta. J Clin Invest. 1993;92(6):2814-2820.

28. Murshed M, Schinke T, McKee MD, Karsenty G. Extracellular matrix mineralization is regulated locally; different roles of two gla-containing proteins. J Cell Biol. 2004;165(5):625-630.

29. Schafer C, Heiss A, Schwarz A, et al. The serum protein alpha 2-Heremans-Schmid glycoprotein/fetuin-A is a systemically acting inhibitor of ectopic calcification. J Clin Invest. 2003;112(3):357-366.

30. Ketteler M, Bongartz P, Westenfeld R, et al. Association of low fetuin-A (AHSG) concentrations in serum with cardiovascular mortality in patients on dialysis: a cross-sectional study. Lancet. 2003;361(9360): 827-833.

31. Lacey DL, Timms E, Tan HL, et al. Osteoprotegerin ligand is a cytokine that regulates osteoclast differentiation and activation. Cell. 1998;93(2):165-176.

32. Simonet WS, Lacey DL, Dunstan CR, et al. Osteoprotegerin: a novel secreted protein involved in the regulation of bone density. Cell. 1997; 89(2):309-319.

33. Bucay N, Sarosi I, Dunstan CR, et al. Osteoprotegerin-deficient mice develop early onset osteoporosis and arterial calcification. Genes Dev. 1998;12(9):1260-1268.

34. Morony S, Tintut Y, Zhang Z, et al. Osteoprotegerin inhibits vascular calcification without affecting atherosclerosis in $1 \mathrm{dlr}(-/-)$ mice. Circulation. 2008;117(3):411-420.

35. Bennett BJ, Scatena M, Kirk EA, et al. Osteoprotegerin inactivation accelerates advanced atherosclerotic lesion progression and calcification in older ApoE-/- mice. Arterioscler Thromb Vasc Biol. 2006;26(9): 2117-2124.

36. Jono S, Ikari Y, Shioi A, et al. Serum osteoprotegerin levels are associated with the presence and severity of coronary artery disease. Circulation. 2002;106(10):1192-1194.

37. Kiechl S, Schett G, Wenning G, et al. Osteoprotegerin is a risk factor for progressive atherosclerosis and cardiovascular disease. Circulation. 2004;109(8):2175-2180.

38. Ozkok A, Caliskan Y, Sakaci T, et al. Osteoprotegerin/RANKL axis and progression of coronary artery calcification in hemodialysis patients. Clin J Am Soc Nephrol. 2012;7(6):965-973.

39. Schoppet M, Schaefer JR, Hofbauer LC. Low serum levels of soluble RANK ligand are associated with the presence of coronary artery disease in men. Circulation. 2003;107(11):e76.

40. Kiechl S, Schett G, Schwaiger J, et al. Soluble receptor activator of nuclear factor-kappa B ligand and risk for cardiovascular disease. Circulation. 2007;116(4):385-391.
41. Helas S, Goettsch C, Schoppet M, et al. Inhibition of receptor activator of NF-kappaB ligand by denosumab attenuates vascular calcium deposition in mice. Am J Pathol. 2009;175(2):473-478.

42. Scatena M, Liaw L, Giachelli CM. Osteopontin: a multifunctional molecule regulating chronic inflammation and vascular disease. Arterioscler Thromb Vasc Biol. 2007;27(11):2302-2309.

43. Wolak T. Osteopontin - a multi-modal marker and mediator in atherosclerotic vascular disease. Atherosclerosis. 2014;236(2):327-337.

44. Shimada T, Kakitani M, Yamazaki Y, et al. Targeted ablation of FGF23 demonstrates an essential physiological role of FGF23 in phosphate and vitamin D metabolism. J Clin Invest. 2004;113(4):561-568.

45. Scialla JJ, Wolf M. Roles of phosphate and fibroblast growth factor 23 in cardiovascular disease. Nat Rev Nephrol. 2014;10(5):268-278.

46. Somjen D, Weisman Y, Kohen F, et al. 25-hydroxyvitamin D3-1alphahydroxylase is expressed in human vascular smooth muscle cells and is upregulated by parathyroid hormone and estrogenic compounds. Circulation. 2005;111(13):1666-1671.

47. Oh J, Weng S, Felton SK, et al. 1,25(OH)2 vitamin D inhibits foam cell formation and suppresses macrophage cholesterol uptake in patients with type 2 diabetes mellitus. Circulation. 2009;120(8):687-698.

48. Giovannucci E, Liu Y, Hollis BW, Rimm EB. 25-hydroxyvitamin D and risk of myocardial infarction in men: a prospective study. Arch Intern Med. 2008;168(11):1174-1180.

49. Bear M, Butcher M, Shaughnessy SG. Oxidized low-density lipoprotein acts synergistically with beta-glycerophosphate to induce osteoblast differentiation in primary cultures of vascular smooth muscle cells. $J$ Cell Biochem. 2008;105(1):185-193.

50. Lomashvili KA, Monier-Faugere MC, Wang X, Malluche HH, O'Neill WC. Effect of bisphosphonates on vascular calcification and bone metabolism in experimental renal failure. Kidney Int. 2009;75(6): $617-625$.

51. Tamura K, Suzuki Y, Hashiba H, Tamura H, Aizawa S, Kogo H. Effect of etidronate on aortic calcification and bone metabolism in calcitriol treated rats with subtotal nephrectomy. J Pharmacol Sci. 2005; 99(1):89-94.

52. Ylitalo R, Oksala O, Ylä-Herttuala S, Ylitalo P. Effects of clodronate (dichloromethylene bisphosphonate) on the development of experimental atherosclerosis in rabbits. J Lab Clin Med. 1994;123(5):769-776.

53. Lerman DA, Prasad S, Alotti N. Denosumab could be a potential inhibitor of valvular interstitial cells calcification in vitro. Int J Cardiovasc Res. 2016;5(1):1.

54. Samelson EJ, Miller PD, Christiansen C, et al. RANKL inhibition with denosumab does not influence 3-year progression of aortic calcification or incidence of adverse cardiovascular events in postmenopausal women with osteoporosis and high cardiovascular risk. J Bone Miner Res. 2014;29(2):450-457.

55. Mullard A. Merck \&Co. drops osteoporosis drug odanacatib. Nat Rev Drug Discov. 2016;15(10):669.

56. Luckman SP, Hughes DE, Coxon FP, Graham R, Russell G, Rogers MJ. Nitrogen-containing bisphosphonates inhibit the mevalonate pathway and prevent post-translational prenylation of GTP-binding proteins, including Ras. J Bone Miner Res. 1998;13(4):581-589.

57. Fleisch HA, Russell RG, Bisaz S, Mühlbauer RC, Williams DA. The inhibitory effect of phosphonates on the formation of calcium phosphate crystals in vitro and on aortic and kidney calcification in vivo. Eur $J$ Clin Invest. 1970;1(1):12-18.

58. Rosenblum IY, Flora L, Eisenstein R. The effect of disodium ethane1-hydroxy-1,1-diphosphonate (EHDP) on a rabbit model of atheroarteriosclerosis. Atherosclerosis. 1975;22(3):411-424.

59. Daoud AS, Frank AS, Jarmolych J, Fritz KE. The effect of ethane1-hydroxy-1,1-d iphosphonate (EHDP) on necrosis of atherosclerotic lesions. Atherosclerosis. 1987;67(1):41-48.

60. Teronen O, Heikkilä P, Konttinen YT, et al. MMP inhibition and downregulation by bisphosphonates. Ann N Y Acad Sci. 1999;878: 453-465.

61. Tintut Y, Patel J, Parhami F, Demer LL. Tumor necrosis factor-alpha promotes in vitro calcification of vascular cells via the cAMP pathway. Circulation. 2000;102(21):2636-2642. 
62. Rogers MJ, Gordon S, Benford HL, et al. Cellular and molecular mechanisms of action of bisphosphonates. Cancer. 2000;88(12 Suppl): 2961-2978.

63. Lehenkari PP, Kellinsalmi M, Näpänkangas JP, et al. Further insight into mechanism of action of clodronate: inhibition of mitochondrial ADP/ ATP translocase by a nonhydrolyzable, adenine-containing metabolite. Mol Pharmacol. 2002;61(5):1255-1262.

64. Price PA, Faus SA, Williamson MK. Bisphosphonates alendronate and ibandronate inhibit artery calcification at doses comparable to those that inhibit bone resorption. Arterioscler Thromb Vasc Biol. 2001;21(5): $817-824$.

65. Price PA, Roublick AM, Williamson MK. Artery calcification in uremic rats is increased by a low protein diet and prevented by treatment with ibandronate. Kidney Int. 2006;70(9):1577-1583.

66. Price PA, Buckley JR, Williamson MK. The amino bisphosphonate ibandronate prevents vitamin D toxicity and inhibits vitamin D-induced calcification of arteries, cartilage, lungs and kidneys in rats. JNutr. 2001; 131(11):2910-2915

67. Kramsch DM, Aspen AJ, Rozler LJ. Atherosclerosis: prevention by agents not affecting abnormal levels of blood lipids. Science. 1981; 213(4515):1511-1512.

68. Persy V, De Broe M, Ketteler M. Bisphosphonates prevent experimental vascular calcification: Treat the bone to cure the vessels? Kidney Int. 2006;70(9):1537-1538.

69. Adami S, Braga V, Guidi G, Gatti D, Gerardi D, Fracassi E. Chronic intravenous aminobisphosphonate therapy increases high-density lipoprotein cholesterol and decreases low-density lipoprotein cholesterol. J Bone Miner Res. 2000;15(3):599-604.

70. Montagnani A, Gonnelli S, Cepollaro C, et al. Changes in serum HDL and LDL cholesterol in patients with Paget's bone disease treated with pamidronate. Bone. 2003;32(1):15-19.

71. Gozzetti A, Gennari L, Merlotti D, et al. The effects of zoledronic acid on serum lipids in multiple myeloma patients. Calcif Tissue Int. 2008;82(4): 258-262.

72. Gonnelli S, Caffarelli C, Tanzilli L, et al. Effects of intravenous zoledronate and ibandronate on carotid intima-media thickness, lipids and FGF-23 in postmenopausal osteoporotic women. Bone. 2014;61: 27-32.

73. Luckish A, Cernes R, Boaz M, et al. Effect of long-term treatment with risedronate on arterial compliance in osteoporotic patients with cardiovascular risk factors. Bone. 2008;43(2):279-283.

74. Koshiyama H, Nakamura Y, Tanaka S, Minamikawa J. Decrease in carotid intima-media thickness after 1-year therapy with etidronate for osteopenia associated with type 2 diabetes. J Clin Endocrinol Metab. 2000;85(8):2793-2796.

75. Celiloglu M, Aydin Y, Balci P, Kolamaz T. The effect of alendronate sodium on carotid artery intima-media thickness and lipid profile in women with postmenopausal osteoporosis. Menopause. 2009;16(4): 689-693.

76. Kanazawa I, Yamaguchi T, Hayashi K, Takase H, Shimizu T, Sugimoto T. Effects of treatment with risedronate and alfacalcidol on progression of atherosclerosis in postmenopausal women with type 2 diabetes mellitus accompanied with osteoporosis. Am J Med Sci. 2010; 339(6):519-524.

77. Delibasi T, Emral R, Erdogan MF, Kamel N. Effects of alendronate sodium therapy on carotid intima media thickness in postmenopausal women with osteoporosis. Adv Ther. 2007;24(2):319-325.

\section{Clinical Interventions in Aging}

\section{Publish your work in this journal}

Clinical Interventions in Aging is an international, peer-reviewed journal focusing on evidence-based reports on the value or lack thereof of treatments intended to prevent or delay the onset of maladaptive correlates of aging in human beings. This journal is indexed on PubMed Central, MedLine,
78. Igase M, Kohara K, Tabara Y, et al. Change in arterial stiffness associated with monthly bisphosphonate treatment in women with postmenopausal osteoporosis. Menopause. 2014;21(9):962-966.

79. Kawahara T, Nishikawa M, Kawahara C, Inazu T, Sakai K, Suzuki G. Atorvastatin, etidronate, or both in patients at high risk for atherosclerotic aortic plaques a randomized, controlled trial. Circulation. 2013; 127(23):2327-2335.

80. Iwamoto J, Sato Y, Uzawa M, Takeda T, Matsumoto H. Comparison of effects of alendronate and raloxifene on lumbar bone mineral density, bone turnover, and lipid metabolism in elderly women with osteoporosis. Yonsei Med J. 2008;49(1):119-128.

81. Nitta K, Akiba T, Suzuki K, et al. Effects of cyclic intermittent etidronate therapy on coronary artery calcification in patients receiving long-term hemodialysis. Am J Kidney Dis. 2004;44(4):680-688.

82. Ariyoshi T, Eishi K, Sakamoto I, Matsukuma S, Odate T. Effect of etidronic acid on arterial calcification in dialysis patients. Clin Drug Investig. 2006;26(4):215-222.

83. Hashiba H, Aizawa S, Tamura K, Kogo H. Inhibition of the progression of aortic calcification by etidronate treatment in hemodialysis patients: long-term effects. Ther Apher Dial. 2006;10(1):59-64.

84. Okamoto M, Yamanaka S, Yoshimoto W, Shigematsu T. Alendronate as an effective treatment for bone loss and vascular calcification in kidney transplant recipients. J Transplant. 2014;2014:269613.

85. Toussaint ND, Lau KK, Strauss BJ, Polkinghorne KR, Kerr PG. Effect of alendronate on vascular calcification in CKD stages 3 and 4: a pilot randomized controlled trial. Am J Kidney Dis. 2010;56(1):57-68.

86. Torregrosa JV, Fuster D, Gentil MA, et al. Open-label trial: effect of weekly risedronate immediately after transplantation in kidney recipients. Transplantation. 2010;89(12):1476-1481.

87. Tankó LB, Qin G, Alexandersen P, Bagger YZ, Christiansen C. Effective doses of ibandronate do not influence the 3-year progression of aortic calcification in elderly osteoporotic women. Osteoporos Int. 2005;16(2): 184-190.

88. Hill JA, Goldin JG, Gjertson D, et al. Progression of coronary artery calcification in patients taking alendronate for osteoporosis. Acad Radiol. 2002;9(10):1148-1152.

89. Lyles KW, Colon-Emeric CS, Magaziner JS, et al. Zoledronic acid in reducing clinical fracture and mortality after hip fracture. $N$ Engl J Med. 2007;357:1799-1809.

90. Kang JH, Keller JJ, Lin HC. Bisphosphonates reduced the risk of acute myocardial infarction: a 2-year follow-up study. Osteoporos Int. 2013;24(1):271-277.

91. Center JR, Bliuc D, Nguyen ND, Nguyen TV, Eisman JA. Osteoporosis medication and reduced mortality risk in elderly women and men. J Clin Endocrinol Metab. 2011;96(4):1006-1014.

92. Wolfe F, Bolster MB, O’Connor CM, Michaud K, Lyles KW, ColónEmeric CS. Bisphosphonate use is associated with reduced risk of myocardial infarction in patients with rheumatoid arthritis. $J$ Bone Miner Res. 2013;28(5):984-991.

93. Kim DH, Rogers JR, Fulchino LA, Kim CA, Solomon DH, Kim SC. Bisphosphonates and risk of cardiovascular events: a meta-analysis. PLoS One. 2015;10(4):e0122646.
CAS, Scopus and the Elsevier Bibliographic databases. The manuscript management system is completely online and includes a very quick and fair peer-review system, which is all easy to use. Visit http://www.dovepress. com/testimonials.php to read real quotes from published authors. 